\title{
Liver energy, atresia and oocyte stage influence fecundity regulation in Northeast Arctic cod
}

\author{
Jon Egil Skjæraasen ${ }^{1, *}$, Richard D. M. Nash ${ }^{2}$, James Kennedy ${ }^{1,3}{ }^{,}$Anders Thorsen ${ }^{2}$, \\ Trygve Nilsen ${ }^{4}$, Olav Sigurd Kjesbu ${ }^{2}$
}

\author{
${ }^{1}$ Department of Biology, University of Bergen, 5020 Bergen, Norway \\ ${ }^{2}$ Institute of Marine Research, PO Box 1870 Nordnes, 5817 Bergen, Norway \\ ${ }^{3}$ Møreforskning Ålesund, PO Box 5075, 5021 Ålesund, Norway \\ ${ }^{4}$ Department of Mathematics, University of Bergen, 5020 Bergen, Norway
}

\begin{abstract}
Marine ecosystems are changing; global warming-induced increases in water temperatures and fishing have caused truncated age structures and small sizes at maturity in many stocks. This may affect both populations' total reproductive output and the link between population demography and recruitment, yet detailed information on fecundity regulation is generally lacking for marine fishes. We therefore examined associations between liver energy, oocyte stage, leading cohort oocyte size $\left(\mathrm{LC}_{20}\right)$, atresia and fecundity for the Northeast Arctic cod (NEAC) Gadus morhua L. from 2006 to 2008 in a comprehensive field and laboratory study. The relationship between the relative liver size (hepatosomatic index, HSI) and specific liver energy content was best described by an asymptotic curve, increasing rapidly at first, then levelling of at $\mathrm{HSI}>6 \%$. $\mathrm{LC}_{20}$ increased towards the spawning season, but was also positively associated with total length. At present there is thus a tendency towards larger NEAC females spawning earlier. The incidence of atresia was highest during the advanced yolk granule stage. Only $1 \%$ of females that reached an $\mathrm{LC}_{20}>300 \mu \mathrm{m}$ absorbed all oocytes and thereby aborted spawning. Potential fecundity showed a parabolic relationship with $\mathrm{LC}_{20}$, peaking around $614 \mu \mathrm{m}$, i.e. approximately on February 1st, and was positively associated with weight, liver energy and, presently, age. In summary, NEAC females that start vitellogenesis will likely spawn. Atresia and fecundity down-regulation appears only to become pronounced close to spawning. Finally, the size-dependent spawning time, which appears to have emerged in the stock recently, may alter the link between population demography and recruitment.
\end{abstract}

KEY WORDS: Gadus morhua · Fecundity regulation · Atresia · Liver energy · Size-dependent spawning time

\section{INTRODUCTION}

Life history theory predicts that females should balance their energy between storage, growth and offspring production in a way that maximises their lifetime reproductive success (Roff 2002). Investment is therefore a function of individual state, where older females are thought to allocate more energy into the present spawning opportunity than younger ones, given that their future reproductive success is expected to be less. Accordingly, in teleosts, larger and older females typically produce relatively more and larger eggs than smaller ones (DeMartini \& Fountain 1981, Hutchings \& Myers 1994, Kjesbu et al. 1996). Theoretically, this along with other size-related reproductive traits (Trippel et al. 1997) has the important implication that age structure affects stock reproductive potential, i.e. the same spawning stock biomass will both in theory (Scott et al. 2006) and practice (Marteinsdottir \& Thorarinsson 1998, Ottersen et al. 2006, Venturelli et al. 2009) lead to different levels of recruitment depending on population structure. 
Marine ecosystems are also changing in ways that may affect allocation patterns. Fishing has severely depleted commercial stocks (Hutchings \& Reynolds 2004), and common denominators of contemporary stocks are a truncated age structure and smaller size at maturity compared to historic data (Trippel et al. 1997, Marteinsdottir \& Thorarinsson 1998, Murawski et al. 2001). Although the importance of an in-depth understanding of the biological processes affecting maturation and thereby indirectly recruitment is acknowledged, essential information is lacking for most marine species.

In terms of fecundity styles, fish can be broadly distinguished into 2 categories: indeterminate and determinate spawners (Hunter et al. 1992, Murua \& Saborido-Rey 2003). Indeterminate spawners recruit new oocytes throughout the spawning period, whereas determinate spawners recruit a finite number of oocytes to the maturing pool prior to spawning. For fish employing the latter strategy, such as the batchspawning Atlantic cod Gadus morhua L., only a downregulation of potential fecundity is possible after the recruitment of oocytes is completed. This occurs through the process of atresia, i.e. the reabsorbtion of vitellogenic oocytes (Woodhead \& Woodhead 1965, Kjesbu et al. 1991, Óskarsson et al. 2002).

The Northeast Arctic cod (NEAC) is now the largest remaining cod stock in the world (ICES 2008). Although NEAC has been the object of close scientific scrutiny, detailed studies on individual fecundity, energy reserves, energy flow or atresia are scarce. Using field samples, Thorsen et al. (2006) found that potential fecundity was positively correlated with female length and condition and decreased due to atresia in the final weeks prior to spawning. This study only included data from late in the maturation cycle (mid-February to mid-March) and was limited to data on weight and length. Thus, this type of sampling design cannot describe allocation patterns in the earlier part of the maturation cycle or supposed peak fecundity (Kjesbu 2009). Neither did this analysis incorporate liver energy as a proxy for fecundity, which is closely linked to egg production in NEAC (Marshall et al. 1998, 1999). Recently, Skjæraasen et al. (2009) examined mechanisms regulating oocyte growth, atresia and spawning omission of NEAC in a laboratory experiment from early August to late January. It was found that females whose leading cohort oocyte size advanced beyond $300 \mu \mathrm{m}$ spawned and that spawning females started oocyte maturation from September to early November, whereas the transition from the cortical alveoli to the yolk granule stage (Tyler \& Sumpter 1996) occurred around $400 \mu \mathrm{m}$. However, there is a clear need to validate these laboratory results with detailed field investigations.
We therefore present data on NEAC collected in a comprehensive field and laboratory study, where individual data on weight, length and age were combined with detailed analyses of fecundity, oocyte stages, the incidence of atresia and liver energy content. This allowed us to investigate allocation and oocyte development patterns on a fine scale hitherto not possible.

\section{MATERIAL AND METHODS}

History of fish. Female NEAC were collected using commercial or research vessels from autumn 2006 to spring 2008 (Fig. 1, Table 1). To examine potential spawners we specifically targeted cod $>59 \mathrm{~cm}$ in total length (Skjæraasen et al. 2009). Aboard the vessels all cod were measured for total length, $1 \mathrm{~cm}$ below, i.e. a female of $60.5 \mathrm{~cm}$ will be given the length $60 \mathrm{~cm}$, and whole body, liver, gonad and gutted weight $(1 \mathrm{~g}$ below). A subsample of the gonad was also stored in neutral buffered formaldehyde $(3.6 \%)$ for later laboratory analyses of oocyte sizes, fecundity and histology. Otoliths were collected for ageing and stock classification (Stransky et al. 2008). In 2007 to 2008, the livers of 164 female cod, which also included samples of nonmaturing fish, were frozen at $-20^{\circ} \mathrm{C}$ immediately after collection for subsequent chemical analyses of liver energy content (see below). Further information of the sampling period, samples obtained and specific analyses performed is given in Table 1 .

Proximate analysis of liver energy content. The liver was partly thawed and 3 tissue pieces of approximately $1 \mathrm{~g}$ each were excised and analysed for dry weight content after one day at $105^{\circ} \mathrm{C}$ followed by calculation of mean and coefficient of variance (CV) $(\mathrm{CV}$ $=100 \times \mathrm{SD} \times \mathrm{mean}^{-1}$ ) for each fish. Likewise, total fat content (wet weight based) of the same triplicates was found gravimetrically with ethyl acetate as extraction solvent (Lauter \& Trams 1962). In both cases the CV was typically around 1 to $2 \%$ and maximally $5 \%$.

Oocyte measurements. All samples were subjected to digital image analyses (Thorsen \& Kjesbu 2001). This method uses the contrast between vitellogenic and previtellogenic oocytes in relation to the set background to specifically select and measure the diameter of vitellogenic oocytes. Only females that could be (1) measured in the automated analyses, i.e. possessed vitellogenic oocytes, and (2) classified as NEAC based on their otolith shape (Rollefsen 1934), were included for any further analyses, which left a total sample size of $379 \mathrm{cod}$ (Table 1). For each measured sample, the size of 200 developing oocytes was reported. From these data the average size of the leading cohort oocytes $\left(\mathrm{LC}_{20}\right)$ ( $\mathrm{n}=20$, average of the largest $10 \%$ of the oocytes) was calculated, since this is indicative of 


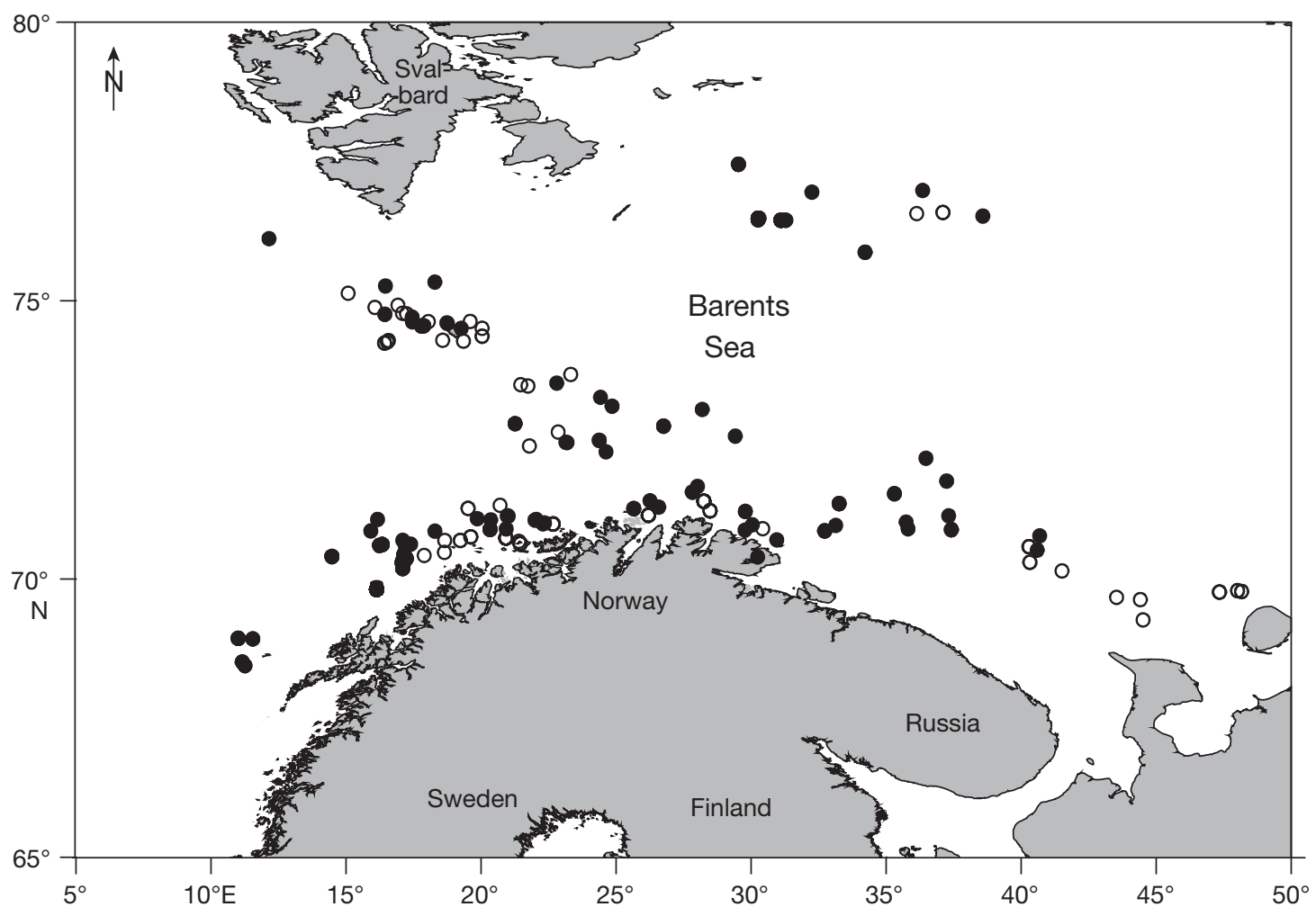

Fig. 1. Capture locations of all cod caught during the 2 field seasons: 2006-2007 (O) and 2007-2008 (O)

the time to start of spawning (Kjesbu 1994). Potential fecundity was calculated as:

$$
F_{\mathrm{p}}=2.139 \times 10^{11} \times \mathrm{OD}^{-2.7} \times \mathrm{OW}
$$

where $F_{\mathrm{p}}$ is potential fecundity, OD is average vitellogenic oocyte diameter, estimated by the image analyser, and OW is ovary weight (g) (Thorsen \& Kjesbu 2001).

Histological analyses. The ovarian samples were prepared for histology using standard protocols for resin embedding (Technovit ${ }^{\circledR}$ 7100) producing $4 \mu \mathrm{m}$ sections stained with $2 \%$ toluidine blue in $1 \%$ sodium tetraborate buffer. Under the light microscope, the presence or absence of atresia was noted. If yolk granules (YG) were found, around 150 YG (vitellogenic) oocytes were examined for atresia. A similar type of estimation was done for the cortical alveoli (CA) stage. Atretic cells were classified as either in the alphastage, containing yolk, or the beta-stage, without yolk (see Hunter \& Macewicz 1985). Females were then grouped under 1 of the following 3 categories (1) no atretic oocytes, (2) some atretic oocytes present, (3) all oocytes atretic, i.e. the females were aborting spawning. This 'rough' estimation of atresia was considered adequate for the scope of the present study, as the tracking of fecundity should implicitly reflect the actual level of atresia (Kjesbu 2009).

Data analyses. Liver energy: As noted above, our chemical analysis was limited to total dry weight content, i.e. the sum of lipids, proteins and glycogen, and lipid dry weight content. Based on the results of Lambert \& Dutil (1997) we assumed the glycogen content to increase linearly from 0 to $5 \%$ of the total liver wet weight in the HSI (hepatosomatic index; HSI $=100 \times$ Liver weight $\times(\text { Total body weight }- \text { Gonad weight })^{-1}$ ) range 0 to 6 . Hence, for HSI values $>6$ we assumed the glycogen content to be $5 \%$ of the liver wet weight. The remaining non-lipid wet weight was considered to be proteins. A priori an exponential increase to a maximum value in lipid content with HSI was expected (e.g. Lambert \& Dutil 1997). To calculate the specific liver energy content (SLEC, in $\mathrm{kJ} \mathrm{g}^{-1}$ ) of liver tissue at different HSI we used the following equivalences of SLEC (y) for different compounds: glycogen, $17.1 \mathrm{~kJ}$ $\mathrm{g}^{-1}$; protein, $23.6 \mathrm{~kJ} \mathrm{~g}^{-1}$; and lipids, $39.5 \mathrm{~kJ} \mathrm{~g}^{-1}$ (Kleiber 1975), against HSI (x). For the latter regression analyses we first examined if the assumption of normally distributed errors and constant variance was met. If not, we then tested for the potential influence of outliers by using Cook's distance, leverage and standardized residuals (Venables \& Ripley 1999). 
Table 1. Overview of samples from maturing female Northeast arctic cods (NEAC) included in the present study. N: number of samples collected from the corresponding vessel (MS: motor ship [commercial vessel]; RV: research vessel), in total 379. Analyses: analyses undertaken on the samples collected. IA: image analyses. HIS: histology. 212 females were collected in the surveys marked with HIS. 198 of these females were examined with histology. LEC: chemical analyses of liver energy content

\begin{tabular}{|lcrc|}
\hline Vessel & Time period & N & Analyses \\
\hline MS 'Ramoen' & Sep 2006 & 8 & IA, HIS \\
MS 'Varegg' & Nov-Dec 2006 & 37 & IA, HIS \\
RV 'G O Sars' & Feb 2007 & 46 & IA, HIS \\
MS 'Amigo' & Feb 2007 & 30 & IA,HIS \\
Andenes I & Feb 2007 & 48 & IA \\
MS 'Prestfjord' & Oct 2007-Mar 2008 & $91^{\text {b }}$ & IA,HIS,LEC \\
RV 'Johan Hjort' & Feb 2008 & 35 & IA \\
RV 'Jan Mayen' & Feb 2008 & 39 & IA \\
Andenes II & Feb 2008 & 45 & IA \\
\multicolumn{4}{|c}{} \\
aSamples at Andenes (69²0' N, 16 ${ }^{\circ}$ 06' E) were from \\
several commercial vessels \\
'Liver energy content was calculated from additional \\
\multicolumn{2}{c}{ samples including none maturing fish as well } \\
\hline
\end{tabular}

Leading cohort oocyte size, atresia and correlates of fecundity and growth: The dependence of $\mathrm{LC}_{20}$ on time of year, total length, residual condition, i.e. the residuals of a regression between length, independent variable, and weight (both log-transformed) and our metric of relative liver energy content, i.e. HSI $\times$ SLEC, was estimated with a stepwise backwards multiple regression. Time of year was coded in the following way: the earliest date for which vitellogenic oocytes were found was given the value 0, e.g. September 3, and later samples a number corresponding to the number of days passed since this date, e.g. October 1 is allocated the number 28. To examine if the incidence of atresia was affected by energy reserves, we compared HSI $\times$ SLEC and residual condition for females (1) possessing or (2) not possessing atretic oocytes, with ANOVAs for each month where we had sufficient samples.

We aimed to establish a biologically realistic statistical model for the explanatory variables of potential fecundity and liver energy content. It is known that fecundity is affected by female size and some metric of condition like liver energy, Fulton's $K$ or relative condition factor (Kjesbu et al. 1998, Marshall et al. 1998, Marteinsdottir \& Begg 2002, Scott et al. 2006). Yoneda \& Wright (2004) also found a positive effect of fish age on fecundity after controlling for size in North Sea cod. Finally, we a priori expected an increase followed by a decline with oocyte stage $\left(\mathrm{LC}_{20}\right)$ in (1) potential fecundity and (2) total liver energy content (TLEC), TLEC = Liver weight $\times$ SLEC, given (1) that some recruited oocytes are likely to be reabsorbed through atresia
(Kjesbu et al. 1991, Thorsen et al. 2006) and (2) liver lipids are metabolised for oocytic yolk production (Tyler \& Sumpter 1996). We initially also allowed the response variables to differ between the 2 sampling seasons. TLEC and female weight were highly correlated and it was therefore not statistically justifiable to include both as explanatory variables in the same model. We therefore incorporated our proxy of relative liver energy content, HSI $\times$ SLEC, instead of TLEC. The following initial model was therefore employed to the fecundity data:

$$
\begin{aligned}
\text { Fecundity }= & \mathrm{LC}_{20}+\left(\mathrm{LC}_{20}\right)^{2}+\text { GWeight }+ \\
& \mathrm{HSI} \times \mathrm{SLEC}+\text { Age }+ \text { Season }
\end{aligned}
$$

where GWeight, i.e. Gutted weight $=$ Total weight Gonad weight - Liver weight. The same principal approach was used to examine temporal patterns in TLEC. However, given that we a priori expect larger females to produce more eggs and hence use more energy for oocyte development than smaller females, we also allowed an interaction term between $\mathrm{LC}_{20}$ and $\left(\mathrm{LC}_{20}\right)^{2}$ and GWeight. We also included residual condition as an independent variable in the latter regression. For both models a hierarchical stepwise procedure where log-likelihood ratio tests were used for model simplification was employed to find the most parsimonious model (Venables \& Ripley 1999).

We then compared length growth across the sampling period for the 3 age classes, i.e. 6, 7 and $8 \mathrm{yr}$, with sufficient sample size. This was done by a linear model where each age class was allowed to have different slope and intercept values. The analyses of energy content, fecundity and growth were done using the base package of $R$ (version 2.9.2) (R Development Core Team 2009).

\section{RESULTS}

\section{Liver energy}

The estimated liver protein content varied between 0 and $20 \%$ of the liver wet weight. The corresponding measured fat content varied between 30 and $80 \%$ and was positively associated with HSI (Fig. 2a, $F_{1,168}=$ 162.6, $\mathrm{p}<0.0001, R^{2}$-adj $=0.49$ ). This relationship and the one between SLEC and HSI was best described by an asymptotic power curve (Fig. 2b, $F_{1,163}=247.8$, p < $0.0001, R^{2}$-adj $\left.=0.60\right)$. When including all data, the assumption of normally distributed errors was not met. Five outliers were identified; each had a standardized residual $>2.5$ (Fig. 2b). After removal of these outliers all assumptions were met. The equation given in Fig. $2 b$ was used to calculate the specific and total energy content for all individual fish referred to below. 

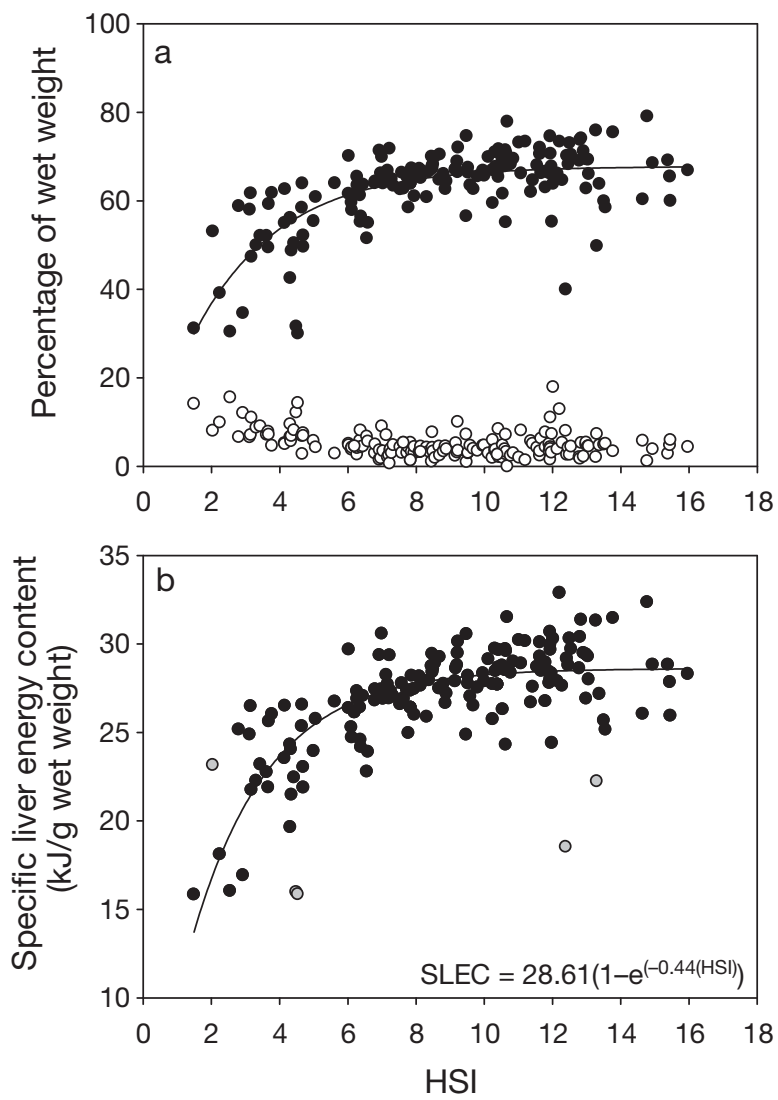

Fig. 2. Gadus morhua. (a) Relationship between (•) lipid content (wet weight based), and (O) protein content against hepatosomatic index $(\mathrm{HSI}=100 \times$ Liver weight $\times($ Total weight Gonad weight $)^{-1}$ ). (b) Calculated specific energy content of the liver as a function of HSI. Equation given is the fitted regression line, which was used for subsequent calculations of energy content. Five outliers (O), i.e. standardised residuals $>2.5$, were excluded when calculating the given regression line

\section{Gonad and $\mathrm{LC}_{20}$ development}

Gonadosomatic index (GSI) and $\mathrm{LC}_{20}$ increased as the spawning season approached (Fig. 3a,b). In the latter case, the stepwise backwards multiple regression yielded a significant effect of both time of year $(B=2.59, \mathrm{p}<0.0001$, i.e. leading cohort oocyte size increased by about $26 \mu \mathrm{m}$ in $10 \mathrm{~d}$, Table 2 ) and female length $(B=1.40, \mathrm{p}<0.0001$, Table 2$)$. For comparison, on February 1, a $70 \mathrm{~cm}$ female's expected $\mathrm{LC}_{20}$ was $610 \mu \mathrm{m}$, whereas a $90 \mathrm{~cm}$ female's $\mathrm{LC}_{20}$ was $638 \mu \mathrm{m}$, i.e. a $20 \mathrm{~cm}$ size difference in length equated to 10 to $11 \mathrm{~d}$ difference in the predicted onset of spawning. There was no effect on $\mathrm{LC}_{20}$ of either HSI $\times$ SLEC or residual condition. Time of year and length explained $72 \%$ of the variation in $\mathrm{LC}_{20}$.

The main transition from the CA to the YG stage occurred around $400 \mu \mathrm{m}$ (Fig. 4). In the population, the
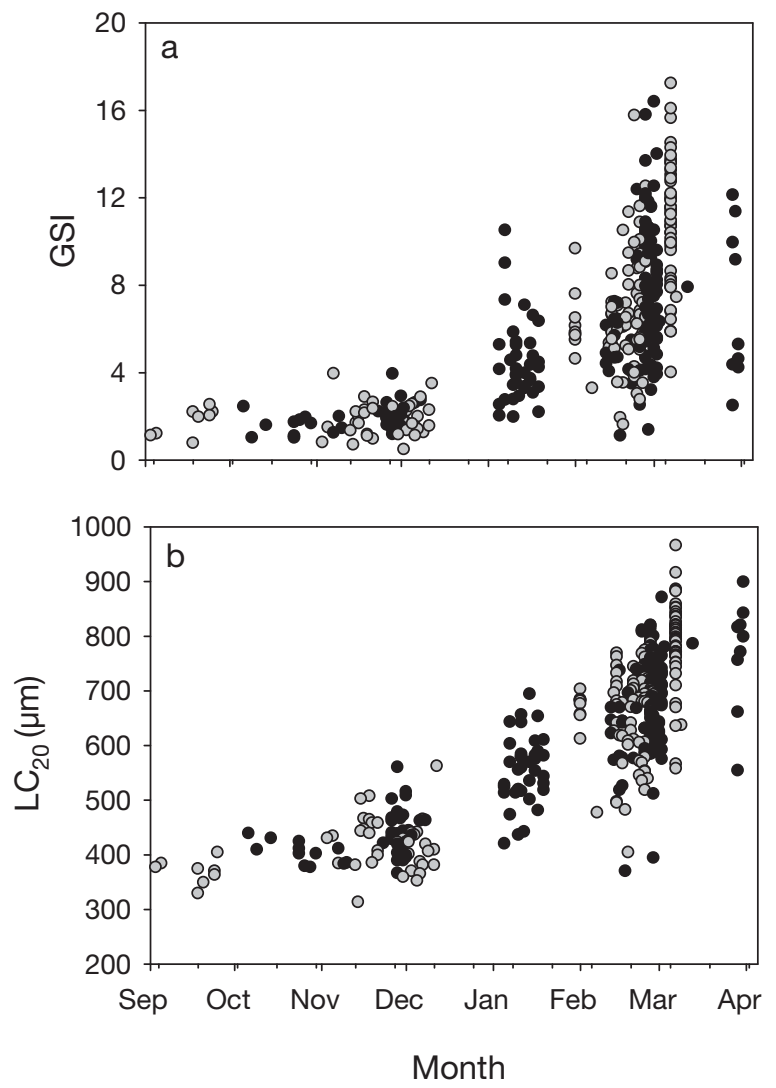

Fig. 3. Gadus morhua. Time course of (a) gonadosomatic in$\operatorname{dex}\left(\right.$ GSI $=100 \times$ Gonad weight $\times$ Total weight $\left.{ }^{-1}\right)$ and $(b)$ leading cohort oocyte size $\left(\mathrm{LC}_{20}\right)$ during the maturation period. (○) 2006-2007; (•) 2007-2008

Table 2. Gadus morhua. Significant explanatory variables of leading cohort oocyte size $\left(\mathrm{LC}_{20}\right)$ variation. Whole model $F_{2,376}=445.64$

\begin{tabular}{|lrrc|}
\hline Parameter & Estimate & \multicolumn{1}{c|}{$t$} & $\mathrm{p}$ \\
\hline Intercept & 103.18 & 3.93 & $<0.0001$ \\
Day of year & 2.59 & 27.86 & $<0.0001$ \\
Female length & 1.40 & 4.44 & $<0.0001$ \\
\hline
\end{tabular}

CA stage dominated in September and October, then decreased sharply in November and by January the CA stage was virtually non-existent (Fig. 5).

\section{Atresia}

The prevalence of atresia was low early in the sampling period, but increased more or less linearly during maturation, and in February $34 \%$ of all sampled females possessed atretic oocytes (Fig. 5). Females with atretic oocytes had lower liver energy content in 


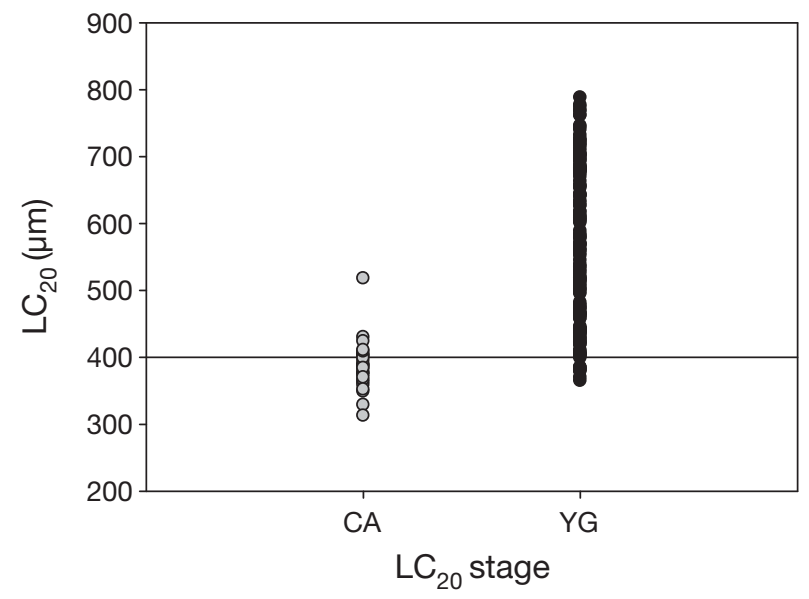

Fig. 4. Gadus morhua. Relationship between leading cohort oocyte size $\left(\mathrm{LC}_{20}\right)$ stage $(\bigcirc)$ cortical alveoli $(\mathrm{CA})$ or $(\bullet)$ yolk granules (YG) and size. (-) Main transition from the CA to the YG stage at a $\mathrm{LC}_{20}$ around $400 \mu \mathrm{m}$

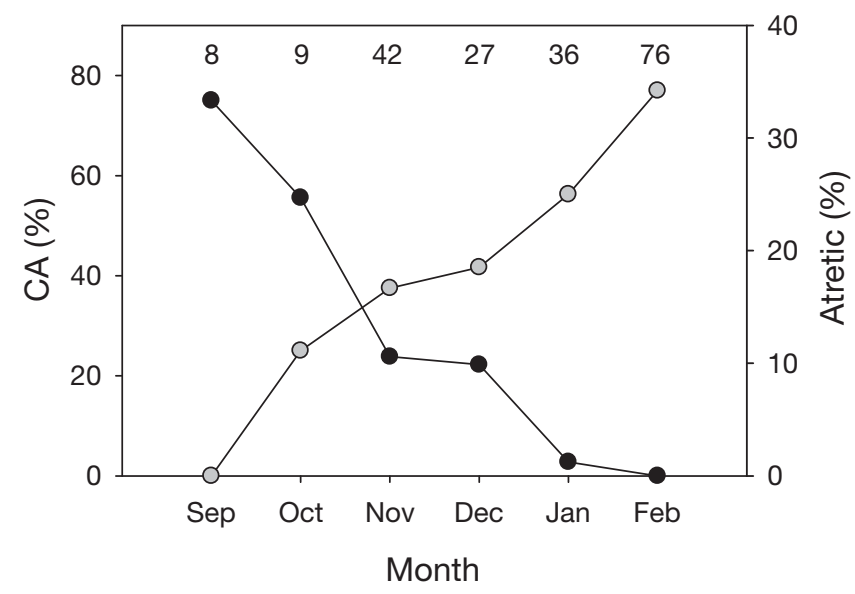

Fig. 5. Gadus morhua. Prevalence of females possessing cortical alveoli (CA) oocytes (•), and females with atretic oocytes (○) in different sampling months. Numbers at the top denote monthly sample size

Table 3. Gadus morhua. Average values of residual condition $($ Res K) and our metric of liver energy content, HSI $\times$ SLEC (HSI: hepatosomatic index, SLEC: specific liver energy content), for females with and without atresia. ${ }^{*}$ Significant difference; $\mathrm{p}<0.01$

\begin{tabular}{|llcrrr|}
\hline \multirow{2}{*}{ Month } & \multicolumn{3}{c}{ Atresia found } & & \multicolumn{2}{c|}{ No atretic oocytes -} \\
& Res K & HSI $\times$ SLEC & & Res K & HSI $\times$ SLEC \\
\hline Nov & -0.0041 & $180^{*}$ & 0.044 & $281^{*}$ \\
Dec & -0.097 & 237 & 0.011 & 297 \\
Jan & -0.031 & 258 & -0.033 & 288 \\
Feb & -0.025 & 188 & 0.016 & 205 \\
\hline
\end{tabular}

November $\left(F_{1,40}=7.95, \mathrm{p}<0.01\right)$, but not significantly so between December to February (Table 3). Residual condition was not associated with the incidence of atresia in either of these months. Even so, values for both our metric of liver energy content and residual condition tended to be consistently lower in females with atretic oocytes (Table 3). The ANOVAs could not be performed for other months due to insufficient samples. Only $2(1.01 \%)$ of the 198 fish examined for intensity of atresia were deemed to undergo complete reabsorption and, thereby, spawning omission.

\section{Energy content, fecundity and growth}

The total liver energy content (TLEC) was significantly negatively correlated with $\mathrm{LC}_{20}$ (Fig. 6), and positively correlated with gutted weight and residual condition (Table 4). There was also a significant effect of season (Table 4) as NEAC had higher liver energy content in 2007-2008.

Fecundity varied greatly from a few hundred thousand to more than 15 million vitellogenic oocytes in the most fecund females (Fig. 7a). The most parsimonious model for fecundity included $\mathrm{LC}_{20},\left(\mathrm{LC}_{20}\right)^{2}$, gutted weight, age and relative liver energy content, which accounted for $78 \%$ of the observed variation in fecundity (Fig. 7b, Table 4). In addition to gutted weight fecundity was also clearly positively associated with both relative liver energy and age. For comparison, at an $\mathrm{LC}_{20}$ of $600 \mu \mathrm{m}$, a 6 yr old $5 \mathrm{~kg}$ female, with an HSI of 10 had an estimated fecundity $13.0 \%$ higher than a female of the same age and gutted weight with an HSI of 2, i.e. an estimated 3.07 million compared to

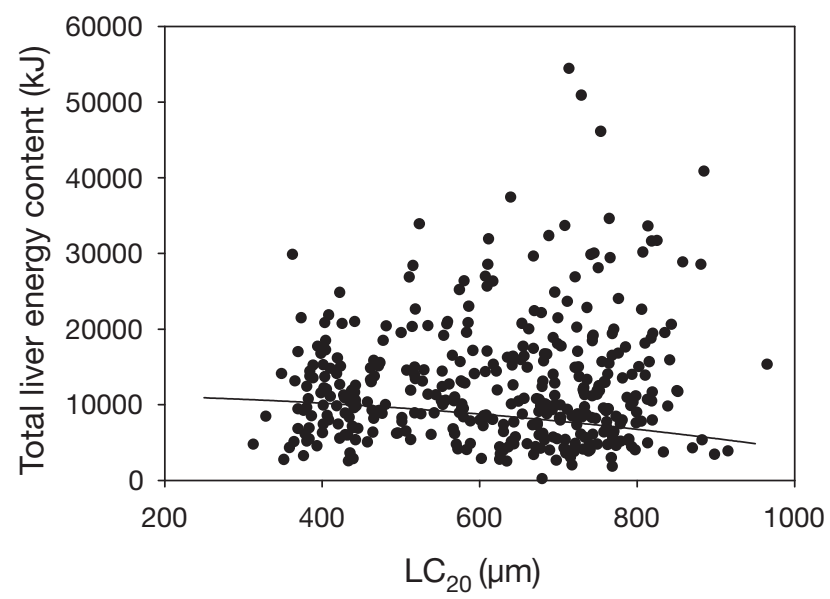

Fig. 6. Gadus morhua. Relationship between total liver energy content (TLEC) and leading cohort oocyte size $\left(\mathrm{LC}_{20}\right)$. The fitted line is the projected liver energy content development for a $5 \mathrm{~kg}$ gutted weight female, with a residual condition factor of 0 , for the 2006-2007 season as calculated from the model given in Table 4 


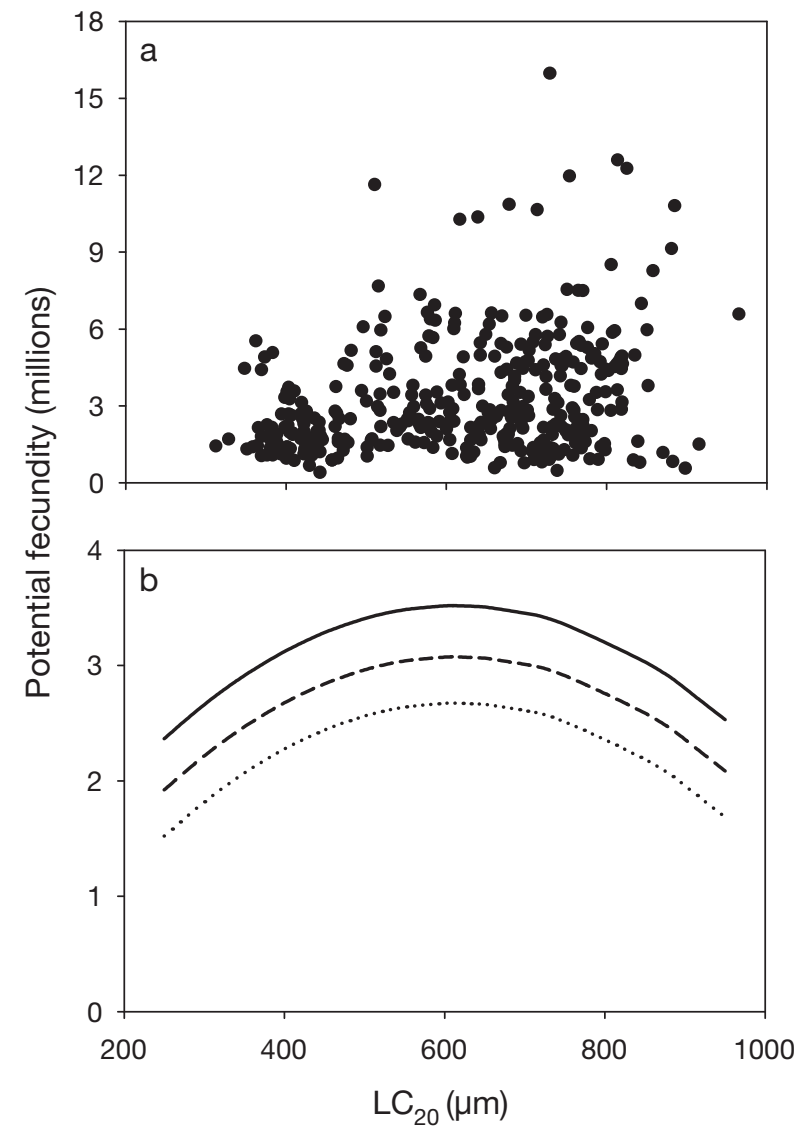

Fig. 7. Gadus morhua. Relationship between potential fecundity and leading cohort oocyte size $\left(\mathrm{LC}_{20}\right)$. (a) Total variation in potential fecundity plotted against $\mathrm{LC}_{20}$. (b) Predicted fecundity as a function of $\mathrm{LC}_{20}$ size for 3 'model' females, demonstrating the effects of differing liver energy and age calculated from the parameters given in Table 4 . The 3 'model' females have a gutted weight of $5 \mathrm{~kg}$ each. (…) $6 \mathrm{yr}$ old female, hepatosomatic index (HSI) of 2; (---) 6 yr old female, HSI of 10; (-) 8 yr old female, HSI of 10
2.67 million vitellogenic oocytes (Fig. 7b). On the other hand, an 8 yr old female, with a gutted weight of $5 \mathrm{~kg}$ and a HSI of 10 produced an estimated $14.4 \%$ more oocytes than the $6 \mathrm{yr}$ old female with the same HSI, i.e. 3.52 million compared to 3.07 million oocytes (Fig. 7b). The $\mathrm{LC}_{20}$ at which maximum fecundity occurred was estimated to be $614 \mu \mathrm{m}$ (95\% CI 566 to $662 \mu \mathrm{m})$, i.e. around February 1 for a $70 \mathrm{~cm}$ cod. We found no differences between 6, 7 and 8 yr old NEAC in body length growth (all p-values $>0.07$, data not shown).

\section{DISCUSSION}

The present study sheds light on several important aspects of oocyte recruitment and fecundity regulation in the determinate batch-spawner, the NEAC. The dedicated, exploratory analyses on fecundity, atresia and liver energy content provides fine-scaled data that allows us to make inferences about life-history traits difficult to target.

\section{Oocyte recruitment and energy flow}

In teleost fish the main yolk protein, vitellogenin, is synthesized from proteins and lipids (Tyler \& Sumpter 1996). In lean fish such as cod, the main storage organ for lipids is the liver (Takama et al. 1985, Kjesbu et al. 1991, Lambert \& Dutil 1997). Due to its direct link to oocyte recruitment and growth, liver energy has therefore been suggested as a proxy for egg production (Marshall et al. 1999, 2000). Liver energy content is not solely a function of liver size, as water content varies substantially with relative liver size (Lambert \& Dutil 1997). It is therefore necessary to establish robust relationships between liver energy content and easily measurable metrics of condition. Lambert \& Dutil (1997) did so for the Gulf of St. Lawrence cod and their relationships have since been applied to other cod stocks (e.g. Skjæraasen et al. 2006), including NEAC (Marshall et al. 1999). The present study indicates that the specific energy content is somewhat higher in NEAC compared to Gulf of St. Lawrence cod for a given liver size, although the liver energy content shows the same general relationship with the hepatosomatic index (HSI). For comparison, the specific energy content of a liver with an HSI of 3 was estimated to be $21.0 \mathrm{~kJ} \mathrm{~g}^{-1}$ for NEAC compared to $17.8 \mathrm{~kJ} \mathrm{~g}^{-1}$ for Gulf of St. Lawrence cod. Our estimated asymptotic maximum 
value of $28.6 \mathrm{~kJ} \mathrm{~g}^{-1}$ is also $3.7 \mathrm{~kJ} \mathrm{~g}^{-1}$ higher. Even so, the similarity of the response curves between these 2 studies (Fig. 2, Lambert \& Dutil 1997) makes it unlikely that the results of past studies, applying the relationship of Lambert \& Dutil (1997) to other stocks, would have been significantly altered by employing the present relationship instead. In both studies a lot of variation remained unexplained. The decrease in energy content with $\mathrm{LC}_{20}$ is in accordance with the utilization of liver energy for yolk production and reduced appetite during maturation (Skjæraasen et al. 2004). Our model predicts similar energy usage regardless of fish size. This is arguably not biologically realistic given that larger females produce more eggs and conversely should utilize more energy. It may be that larger females are able to replenish the energy used for oocyte development through feeding to a greater extent than smaller females, but such size-specific feeding has yet to be supported statistically (Michalsen et al. 2008).

Successful reproduction in marine pelagic spawners includes larvae finding sufficient food. NEAC larvae are connected to the spring Calanus finmarchicus nauplii peak production, i.e. what became known as the critical period (Hjort 1914) or match-mismatch hypothesis (Cushing 1974, 1975). We found that $\mathrm{LC}_{20}$ increased as the spawning season approached, yielding a positive relationship with time of year, but also with female length. $\mathrm{LC}_{20}$ is indicative of the start of spawning (Kjesbu 1994) and highly fecund, large females will thus to a larger extent be present during the early part of the spawning season. This could have positive consequences for successful reproduction and recruitment due to an increased temporal overlap with the zooplankton peak for the first-feeding cod larvae (Solemdal 1997). However, this would probably be only one contributory factor to recruitment variability since many other factors can affect the survival of offspring from early life history to maturity and joining the adult population. More interestingly, no such link between female length and spawning time was found for NEAC in the 1980s (Kjesbu 1994). Ongoing research indicates that elevated water temperatures may create such a coupling between female length and spawning time due to different physiological responses at a large and small body size in agreement with general thermal tolerance theory (see Kjesbu et al. 2010 and references therein). Our observations tentatively agree with this as there has been a consistent trend towards higher temperatures in the water masses occupied by NEAC over the last decades (Ottersen et al. 2006). At present the length-based separation in spawning time is small, but, if temperature related, it may become more pronounced with expected water warming (IPCC 2007). This is an important topic for future research.

\section{Fecundity regulation}

Fecundity showed a parabolic relationship with leading cohort size clearly illustrating the recently introduced concept of 'down-regulation' in the final months prior to spawning (Kennedy et al. 2009). Downregulation likely occurs to some extent in all ovaries (Kjesbu 2009), but is accelerated in fish in poor condition (e.g. Kjesbu et al. 1991, Kennedy et al. 2007). We only found partial support for the latter explanation in the present study. Although both residual condition and liver energy content was generally lower in females with compared to females without atresia, this difference was only significant for liver energy content in November (Table 3). It may be that atresia in NEAC reflects temporal changes in energy reserves rather than energy reserves per se as has been shown in plaice Pleuronectes platessa L. (Kennedy et al. 2008). However, the estimated down-regulation (Fig. 7b) suggests that all females show atresia at some point in the later part of the maturity cycle. Thus, absence of atresia in several females is a likely indicator of low overall, but not necessarily zero, atresia levels in these females or, alternatively, that our sample was obtained before or after the atretic window of that particular fish. Interestingly, our estimated peak fecundity, $\mathrm{LC}_{20}=614 \mu \mathrm{m}$, occurs quite late. This suggests that (1) the window for oocyte recruitment remains open until the $\mathrm{LC}_{20}$ are well into the YG stages, but perhaps more importantly that (2) atresia becomes pronounced only close to spawning. The latter is also supported by monthly examination of the frequency of females with atretic oocytes. Notably, complete reabsorption of oocytes only occurred in $1.0 \%$ of the maturing females. Thus it seems that with little exception, females that truly start vitellogenesis, i.e. $\mathrm{LC}_{20}>300 \mu \mathrm{m}$, will spawn. This latter result, and the transition from the CA to the YG stage around $400 \mu \mathrm{m}$, closely mimics the results obtained on NEAC in the laboratory (Skjæraasen et al. 2009). Based on the sharp reduction in the frequency of females whose $\mathrm{LC}_{20}$ was at the CA stage from October to November, i.e. females that have fairly recently started maturation, it would seem that females that are to spawn in the coming spring join the maturing fraction before the end of November. This is in accordance with the suggested onset of maturation from previous studies on NEAC (Kjesbu 1994, 2010). Female fecundity was also positively associated with female size, i.e. weight, and our metric of liver energy content. In our field study we have not considered the effect of feeding, logically improving the energetic status of each female and thereby its liver energy content, complicating straightforward interpretations of the present data. It is well known from experiments on cod that there is an inverse relationship between body and gonad 
growth during vitellogenesis (Taranger et al. 2006). In light of the earlier mentioned generally reduced appetite at advanced maturity, the fecundity reduction at $\mathrm{LC}_{20}>620 \mu \mathrm{m}$ is likely due to insufficient energy resources to fuel the on-going oocytic yolk uptake in these long-migratory fish.

The present data indicate that older females produced more eggs than younger ones of similar size. Increased reproductive investment theoretically comes at the expense of growth (Roff 2002) and likely survival, as poor condition increases post-spawning mortality in gadoids (Dutil \& Lambert 2000, Lambert \& Dutil 2000). Thus, from a life-history perspective, younger females would be expected to invest less in fecundity and more in growth than older ones, whose future reproductive success is expected to be low (Houston \& McNamara 1999, Clark \& Mangel 2000, Roff 2002). We clearly find support for the former at present, but, arguably, not the latter as there were no growth differences between females 6 to $8 \mathrm{yr}$ old. However, NEAC females of 6 to $8 \mathrm{yr}$ are not particularly 'old' and it may be that a growth related trade-off would have emerged if we had had more samples from older females. Moreover, it may be that, if present for NEAC, the trade-off is more related to storage and thereby survival than growth per se. For the North Sea cod, similar patterns of age-dependent reproductive investment after controlling for fish size have been attributed to fisheries-induced genetic change, given that such patterns were not observed in the same stock in the late 1960's (Yoneda \& Wright 2004). Investigation of the IMR (Institute of Marine Research) time series of fecundity data collected at Andenes $\left(69^{\circ} 20^{\prime} \mathrm{N}, 16^{\circ} 06^{\prime} \mathrm{E}\right)$ indicates that this age-dependent investment has been seen intermittently in the last decades for NEAC (O. S. Kjesbu unpubl.). Arguably, an age-dependent response to environmental conditions is therefore a more likely explanation for our results, but this could also be due to insufficient sample sizes in some years. Consequently, identification of the causes behind the presently observed allocation pattern should be further tested.

\section{CONCLUSIONS}

The results highlight a number of important processes for oocyte recruitment and fecundity regulation; females that reach a $\mathrm{LC}_{20}>300 \mu \mathrm{m}$ will, almost without exception, spawn. Atresia and down-regulation only becomes pronounced during the final period prior to spawning for maturing females. NEAC females now tend to be temporally structured in spawning time according to length, which may affect the link between population demography and recruitment. There were also indications of an age effect on fecundity, not reported earlier. Finally, we have established a liver energy model for the NEAC and used this successfully to predict fecundity and we have detailed the phenomenon of fecundity down-regulation. This was achieved by a comprehensive sampling programme on adult female cod in the Barents Sea covering all stages of oocyte growth, instead of the traditional programme limited to prespawners only.

Acknowledgements. The study was funded by the Research Council of Norway projects 'Timing and determination of fecundity and skipped spawning: implications for stockrecruitment theory of determinate spawners' (173341/S40) and 'The occurrence of skipped spawning and its importance for population dynamics in Northeast Arctic gadoids' (190228). We thank V. Mangerud, M. Krüger-Johnsen, M. Fonn and B. Njøs Strand for assistance during the experiments and 4 anonymous referees for their helpful comments and advice.

\section{LITERATURE CITED}

Clark CW, Mangel M (2000) Dynamic state variable models in ecology. Oxford University Press, New York

Cushing DH (1974) The natural regulations of populations. In: Harden Jones FR (ed) Sea fisheries research. Elek Science, London, p 399-412

Cushing DH (1975) Marine ecology and fisheries. Cambrigde University Press, New York

DeMartini EE, Fountain RK (1981) Ovarian cycling frequency and batch fecundity in the queenfish, Seriphus politusattributes representative of serial spawning fishes. Fish Bull 79:547-560

> Dutil JD, Lambert Y (2000) Natural mortality from poor condition in Atlantic cod (Gadus morhua). Can J Fish Aquat Sci $57: 826-836$

Hjort J (1914) Fluctuations in the great fisheries of northern Europe viewed in light of biological research. Rapp P-V Reùn Cons Int Explor Mer 20:1-228

Houston AI, McNamara JM (1999) Models of adaptive behaviour: An approach based on state. Cambridge University Press, Cambridge, UK

Hunter JR, Macewicz BJ (1985) Rates of atresia in the ovary of captive and wild northern anchovy, Engraulis mordax. Fish Bull 83:119-136

Hunter JR, Macewicz BJ, Lo NCH, Kimbrell CA (1992) Fecundity, spawning, and maturity of female dover sole Microstomus pacificus, with an evulation of assumptions and precision. Fish Bull 90:101-128

- Hutchings JA, Myers RA (1994) What can be learned from the collapse of a renewable resource-Atlantic cod, Gadus morhua, of Newfoundland and Labrador. Can J Fish Aquat Sci 51:2126-2146

Hutchings JA, Reynolds JD (2004) Marine fish population collapses: consequences for recovery and extinction risk. Bioscience 54:297-309

ICES (2008) Report of the Arctic Fisheries Working Group (AFWG). ICES CM $\backslash A C O M: 0$, ICES Headquarters, Copenhagen

IPCC (2007) Climate Change 2007: synthesis report. Contributions of working groups I, II and III to the fourth assessment report of the intergovernmental panel of climate change. IPCC, Geneva, Switzerland 
Kennedy J, Witthames PR, Nash RDM (2007) The concept of fecundity regulation in plaice (Pleuronectes platessa) tested on 3 Irish Sea spawning populations. Can J Fish Aquat Sci 64:587-601

Kennedy J, Witthames PR, Nash RDM, Fox CJ (2008) Is fecundity in plaice (Pleuronectes platessa L.) down-regulated in response to reduced food intake during autumn? J Fish Biol 72:8-92

Kennedy J, Gundersen AC, Boje J (2009) When to count your eggs: Is fecundity in Greenland halibut (Reinhardtius hippoglossoides W.) down-regulated? Fish Res 100:260-265

Kjesbu OS (1994) Time of start spawning in Atlantic cod (Gadus morhua) females in relation to vitellogenic oocyte diameter, temperature, fish length and condition. J Fish Biol 45:719-735

Kjesbu OS (2009) Applied fish reproductive biology: contribution of individual reproductive potential to recruitment and fisheries management. In: Jakobsen $T$, Fogarty $M$, Megrey BA, Moksness E (eds) Fish reproductive biology: implications for assessment and mangement. John Wiley and Sons, Hoboken, NJ, p 293-332

Kjesbu OS, Klungsøyr J, Kryvi H, Witthames PR, Greer Walker M (1991) Fecundity, atresia, and egg size of captive Atlantic cod (Gadus morhua) in relation to proximate body composition. Can J Fish Aquat Sci 48:2333-2343

Kjesbu OS, Solemdal P, Bratland P, Fonn M (1996) Variation in annual egg production in individual captive Atlantic cod (Gadus morhua). Can J Fish Aquat Sci 53:610-620

Kjesbu OS, Witthames PR, Solemdal P, Walker MG (1998) Temporal variations in the fecundity of Arcto-Norwegian cod (Gadus morhua) in response to natural changes in food and temperature. J Sea Res 40:303-321

Kjesbu OS, Righton D, Krüger-Johnsen M, Thorsen A, Michalsen K, Fonn M, Witthames PR (2010) Thermal dynamics of ovarian maturation in Atlantic cod (Gadus morhua). Can J Fish Aquat Sci 67:605-625

Kleiber M (1975) The fire of life: an introduction to animal energetics. Krieger Publishing, New York

> Lambert Y, Dutil JD (1997) Can simple condition indices be used to monitor and quantify seasonal changes in the energy reserves of Atlantic cod (Gadus morhua)? Can J Fish Aquat Sci 54:104-112

> Lambert Y, Dutil JD (2000) Energetic consequences of reproduction in Atlantic cod (Gadus morhua) in relation to spawning level of somatic energy reserves. Can J Fish Aquat Sci 57:815-825

Lauter CJ, Trams EG (1962) A spectrophotometric determination of sphingosine. J Lipid Res 3:136-138

Marshall CT, Kjesbu OS, Yaragina NA, Solemdal P, Ulltang Ø (1998) Is spawner biomass a sensitive measure of the reproductive and recruitment potential of Northeast Arctic cod? Can J Fish Aquat Sci 55:1766-1783

Marshall CT, Yaragina NA, Lambert Y, Kjesbu OS (1999) Total lipid energy as a proxy for total egg production by fish stocks. Nature 402:288-290

- Marshall CT, Yaragina NA, Ådlandsvik B, Dolgov AV (2000) Reconstructing the stock-recruit relationship for Northeast Arctic cod using a bioenergetic index of reproductive potential. Can J Fish Aquat Sci 57:2433-2442

- Marteinsdottir G, Begg GA (2002) Essential relationships incorporating the influence of age, size and condition on variables required for estimation of reproductive potential in Atlantic cod Gadus morhua. Mar Ecol Prog Ser 235: 235-256

> Marteinsdottir G, Thorarinsson K (1998) Improving the stockrecruitment relationship in Icelandic cod (Gadus morhua) by including age diversity of spawners. Can J Fish Aquat Sci 55:1372-1377

Michalsen K, Johannesen E, Bogstad B (2008) Feeding of mature cod (Gadus morhua) on the spawning grounds in Lofoten. ICES J Mar Sci 65:571-580

Murawski SA, Rago PJ, Trippel EA (2001) Impacts of demographic variation in spawning characteristics on reference points for fishery management. ICES J Mar Sci 58: 1002-1014

Murua H, Saborido-Rey F (2003) Female reproductive strategies of marine fish species of the North Atlantic. J Northwest Atl Fish Sci 33:23-31

Óskarsson GJ, Kjesbu OS, Slotte A (2002) Predictions of realised fecundity and spawning time in Norwegian spring-spawning herring (Clupea harengus). J Sea Res 48: $59-79$

Ottersen G, Hjermann DØ, Stenseth NC (2006) Changes in spawning stock structure strengthen the link between climate and recruitment in a heavily fished cod (Gadus morhua) stock. Fish Oceanogr 15:230-243

R Development Core Team (2009). R: a language and environment for statistical computing. R Foundation for Statistical Computing, Vienna, Austria. ISBN 3-900051-07-0, URL http://www.r-project.org/

Roff DA (2002) Life history evolution. Sinauer, Sunderland, MA

Rollefsen G (1934) The cod otolith as a guide to race, sexual development and mortality. Rapp P-V Reùn Cons Int Explor Mer 88:1-5

Scott BE, Marteinsdottir G, Begg GA, Wright PJ, Kjesbu OS (2006) Effects of population size/age structure, condition and temporal dynamics of spawning on reproductive output in Atlantic cod (Gadus morhua). Ecol Modell 191: $383-415$

Skjæraasen JE, Salvanes AGV, Karlsen O, Dahle R, Nilsen T, Norberg B (2004) The effect of photoperiod on sexual maturation, appetite and growth in wild Atlantic cod (Gadus morhua L.). Fish Physiol Biochem 30:163-174

> Skjæraasen JE, Nilsen T, Kjesbu OS (2006) Timing and determination of potential fecundity in Atlantic cod (Gadus morhua). Can J Fish Aquat Sci 63:310-320

Skjæraasen JE, Kennedy J, Thorsen A, Fonn M, Njøs-Strand B, Mayer I, Kjesbu OS (2009) Mechanisms regulating oocyte recruitment and skipped spawning in Northeast Arctic cod (Gadus morhua L.). Can J Fish Aquat Sci 66: 1582-1596

> Solemdal P (1997) Maternal effects - a link between the past and the future. J Sea Res 37:213-227

Stransky C, Baumann H, Fevolden SE, Harbitz A and others (2008) Separation of Norwegian coastal cod and Northeast Arctic cod by outer otolith shape analysis. Fish Res 90:26-35

Takama K, Love RM, Smith GL (1985) Selectivity in mobilisation of stored fatty acids by maturing cod, Gadus morhua L. Comp Biochem Physiol B 80:713-718

> Taranger GL, Aardal L, Hansen T, Kjesbu OS (2006) Continuous light delays sexual maturation and increases growth of Atlantic cod (Gadus morhua L.) in sea cages. ICES J Mar Sci 63:365-375

> Thorsen A, Kjesbu OS (2001) A rapid method for estimation of oocyte size and potential fecundity in Atlantic cod using a computer-aided particle analysis system. J Sea Res 46: 295-308

> Thorsen A, Marshall CT, Kjesbu OS (2006) Comparison of various potential fecundity models for north-east Arctic cod Gadus morhua, L. using oocyte diameter as a standardizing factor. J Fish Biol 69:1709-1730

Trippel EA, Kjesbu OS, Solemdal P (1997) Effects of adult age 
and size structure on reproductive output in marine fishes. In: Chambers RC, Trippel EA (eds) Early life history and recruitment in fish populations. Chapman \& Hall, London, p 31-62

Tyler CR, Sumpter JP (1996) Oocyte growth and development in teleosts. Rev Fish Biol Fish 6:287-318

Venables WN, Ripley BD (1999) Modern applied statistics with S-PLUS, 3rd edn. Springer, New York

> Venturelli PA, Shuter BJ, Murphy CA (2009) Evidence for harvest-induced maternal influences on the reproductive

Editorial responsibility: Stylianos Somarakis,

Heraklion, Greece rates of fish populations. Proc Biol Sci 276:919-924

Woodhead AD, Woodhead PMJ (1965) Seasonal changes in the physiology of Barents Sea cod, Gadus morhua L., in relation to its environment. I. Endocrine changes particularly affecting migration and maturation. Int Comm Northwest Atl Fish Spec Publ. 6:691-715

Yoneda M, Wright PJ (2004) Temporal and spatial variation in reproductive investment of Atlantic cod Gadus morhua in the northern North Sea and Scottish west coast. Mar Ecol Prog Ser 276:237-248

Submitted: July 15, 2009; Accepted: January 7, 2010

Proofs received from author(s): March 26, 2010 